\title{
11
}

\section{Taking Account of Land-Sea Interactions in Marine Spatial Planning}

\author{
Sue Kidd, Hannah Jones, and Stephen Jay
}

\section{Introduction}

As the opening chapter in this book reveals, since the first major international conference on marine/maritime spatial planning (MSP) organised by the Intergovernmental Oceanographic Commission of United Nations Educational, Scientific, and Cultural Organization (UNESCO) in 2006, MSP has emerged as a significant new direction in global governance with systems of MSP being established for the first time in coastal states across the world. It therefore appears that, for many, MSP is seen as a key mechanism to achieve more effective planning and management of human relationships with the sea. One of the leading definitions of MSP as 'a public process of analysing and allocating the spatial and temporal distribution of human activities in marine areas to achieve ecological, economic and social objectives that have been specified through a political process' (Ehler and Douvere 2009) provides an insight into the nature of these MSP developments which focus on improving governance of human activities in the marine environment. There is no doubt such efforts are needed not only to respond to growing human use of the sea and rising demands on marine space and potential for

\footnotetext{
S. Kidd $(\bowtie) \bullet$ S. Jay

Department of Geography and Planning, University of Liverpool, Liverpool, UK e-mail: suekidd@liverpool.ac.uk

H. Jones

School of Environmental Sciences, University of Liverpool, Liverpool, UK
} 
conflict between different marine activities but also to growing understanding of the scale of deterioration in the health of marine ecosystems and its connection with current patterns of human development. However, while recent MSP advances must be welcomed, the purpose of this book is to critically reflect on this experience and explore future directions for this embryonic form of governance. This chapter does this from a Land-Sea Interaction (LSI) perspective and raises questions about the role and limitations of MSP in addressing sustainable development of the world's oceans as many of the issues it is concerned with are inextricably connected to activity on the land. The chapter starts by identifying LSI considerations that are evident in some of the key documents that are guiding the establishment of MSP across the world. It then sets out a framework for understanding LSI and explores the different dimensions identified with particular reference to examples from European experience where LSI issues have become a renewed focus of concern in recent times. The chapter ends with an exploration of how LSI matters might inform future directions for MSP and may be heralding a new era of Territorial Spatial Planning (TSP), which spans both land and sea.

\section{LSI and MSP: Directions from International Law and Guidance on MSP}

A key reference point for all those involved in the development of MSP is the 1982 United Nations Convention of the Law of the Sea (UNCLOS) as this is one of the most significant international legal frameworks guiding human relations with the world's oceans (Maes 2008; Soininen and Hassan 2015). A reading of UNCLOS from an MSP and LSI perspective provides some interesting insights as it is evident that related considerations permeate key aspects of the convention. For example, the economic significance of the sea to landward communities is reflected in the preamble to the document which states that the convention aims 'to contribute to the realization of a just and equitable international economic order which takes into account the interests and needs of mankind as a whole and, in particular, the special interests and needs of developing countries, whether coastal or land-locked' (United Nations General Assembly 1982, preamble). This aim is perhaps reflected most prominently in the sections related to protection of rights of innocent passage for ships of all nations. Recognition of key shipping routes and port infrastructure and the location of other sea uses in a way which is consistent with their continuing operation is a central concern for MSP (Nautical Institute and World Ocean Council 2013), and its significance cannot be overstated. It is 
important because over 80 per cent of global trade is carried on board ships and seaborne trade is inextricably connected to the activities and well-being of the world economy (United Nations Conference on Trade and Development 2017) and indeed most aspects of human life in all countries. LSI perspectives are also evident in the sections in UNCLOS related to protection and preservation of the marine environment. For example, Article 194 requires states to take measures to deal with all sources of pollution of the marine environment including those from land-based sources. Many see protection of the marine environment as another critical aspect of MSP (Douvere 2008; Foley et al. 2010; Ehler 2018), but UNCLOS raises interesting questions about the nature of MSP's role and its limitations in dealing with this agenda which extends well beyond ocean shores.

It should be noted that UNCLOS predates the development of the modern era of MSP which evolved at least in part from experimentation from the 1970s onwards with Integrated Coastal Zone Management (ICZM sometimes called Integrated Coastal Management (ICM)). Its emergence as a significant new field of global governance in its own right was reflected in the publication in 2009 of a step-by-step guide to MSP by UNESCO (Ehler and Douvere 2009). This document remains an important global reference point for MSP (Ehler 2014; Pınarbaşı et al. 2017), and it therefore also seems relevant to reflect on its mention of LSI issues here. These are first addressed in its discussion of ICZM which it acknowledges played a key part in demonstrating the need for integrated planning and management of human relationships with the marine environment. However, it notes that ICZM at that point in time tended to be focussed on a narrow coastal strip — both landward and seawardand rarely extended inland to cover, for example, coastal watersheds or seawards to include all of the territorial seas or Exclusive Economic Zones (EEZs) where significant human interactions also occurred. In contrast to ICZM, the guide saw MSP as focusing on the human use of marine spaces and envisaged it as 'the missing piece that can lead to truly integrated planning from coastal watersheds to marine ecosystems' (Ehler and Douvere 2009, p. 21). This line of thinking is developed further in the guide's discussion of MSP and Ecosystem-based Management which it described as an integrated approach to management that considers the entire ecosystem, including humans with the goal being to maintain an ecosystem in a healthy, productive and resilient condition so that it can provide the goods and services humans want and need. In this context, attention is drawn to the need to recognise the interconnectedness among systems, such as among air, land and sea. In this way, the guide is a useful reminder of early thinking about the scope of MSP with its marine focus and its place within a wider governance architecture addressing LSI issues. 
More recently, for countries within the European Union (EU), the 2014 MSP Directive has become a key document guiding MSP development. It is also emerging as a reference point for MSP practice in other parts of the world as the European Commission joins forces with UNESCO to promote the roll out of MSP process worldwide (UNESCO and European Commission 2017). Here too LSI considerations are evident. For example, Article 6 of the Directive indicates that one of the minimum requirements of MSP is that LSI should be taken into account, while Article 7 says that Member States may achieve this through the MSP process itself or by other formal or informal processes, such as ICZM in which case, the outcome must be reflected in the maritime spatial plans. Beyond this, the Directive is significant in noting that MSP has an important role in promoting coherence with other relevant processes related to LSI and in this way it establishes a legal basis for MSP authorities to make connections inland (EC 2014). It is perhaps for these reasons that LSI issues have been a source of much interest in recent MSP discussions in Europe which have prompted action across a range of fronts. This chapter draws upon this experience to help develop a closer understanding of the connections between LSI, MSP and wider systems of 'territorial' governance.

\section{A Framework for Considering Land-Sea Interactions}

However, before discussing recent European experience related to LSI, it is important to acknowledge that LSI-related work is by no means new or indeed unique to this part of the world. One illustration of this is the LandOcean Interactions in the Coastal Zone (LOICZ) project which was established in 1993 as a core element of the International Geosphere-Biosphere Programme (IGBP). This has produced many helpful LSI-related outputs over the years (Ramesh et al. 2015). With an initial focus on the biology, chemistry and physics of the coastal zone, it has more recently extended its research scope to include social, political and economic sciences to better address the human dimensions of LSI. Since 2015, LOICZ has become a core project of the new Future Earth initiative under the new name of Future Earth Coasts (Future Earth Coasts 2018) and this is likely to be a key point of reference for those with an interest in LSI in years to come.

Beyond research associated with the LOICZ project, LSI-related activities have been longstanding in Europe and an early expression of this was also focussed around the coastal zone where interactions are arguably at 
their most obvious and intense. This took the form of activity related to ICZM and included projects which formed part of the EU Demonstration Programme on ICZM which ran from 1996 to 1999. This informed the development of eight ICZM principles (EC 1999) which at first sight can seem surprisingly lacking in specific reference to LSI. However, closer examination reveals that core areas for LSI consideration are identified including interactions within and between natural systems and human activity (e.g. Principles 1 and 5) and in governance arrangements-involving relevant administrative bodies at different levels (Principle 7) and making use of a combination of instruments to facilitate coherence (Principle 8). In this way, the ICZM principles mirror to some extent the LSI research areas identified in the LOICZ programme and seem to confirm these as central aspects to consider in scoping LSI concerns. Beyond this however, it is worth noting that the ICZM principles set out a number of operational points which also seem to be of relevance to those involved in addressing LSI matters. These include the need to take a long-term perspective (Principle 2), adopt an adaptive management approach (Principle 3), recognise local specificity (Principle 4) and involve all parties (Principle 6).

More recently, various EU institutions have supported further investigation into LSI matters. For example, in 2013, The European Observation Network for Territorial Development and Cohesion (ESPON) published the findings of its ESaTDOR project which examined territorial development opportunities and risks in European Seas (University of Liverpool 2013). Through an analysis of EU-wide data sets related to economic activity, energy and pipelines and cables, and transport and environment, the study developed a typology of European maritime regions reflecting the varying intensity of LSI. The typology distinguished European Core, Regional Hub, Transition, Rural and Wilderness regions (see Fig. 11.1). The study is of interest in setting out a methodology to enable comparable analysis of land and sea data and using this to identify LSI hotspots and cold spots covering both land and sea areas. Equally, some may find helpful its exploration of the potential policy implications arising from the definition of maritime regions with different levels of LSI intensity.

ESPON is funding a follow-up project on LSI called MSP-LSI, which is extending understanding in particular of landward economic linkages of key maritime sectors drawing upon the value chain analysis outlined below. The project will produce guidelines for both MSP and terrestrial planning agencies on how best to manage LSI, The results will be published in 2019. 


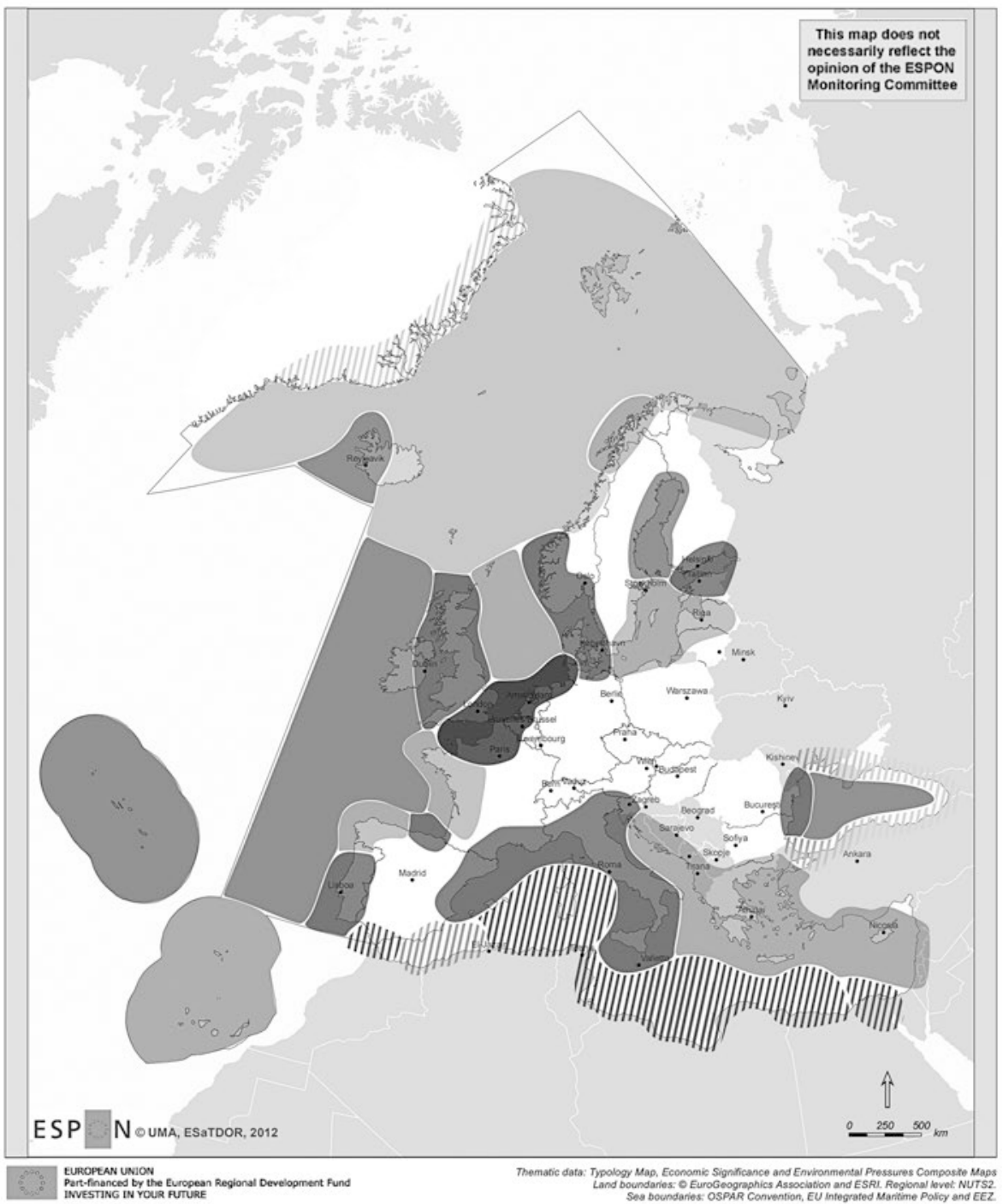

Regions derived from typology map

\begin{tabular}{l}
\hline European Core \\
Regional Hub \\
Transition \\
Rural \\
Wilderness \\
\end{tabular}

This schematic typology map shows Europe's coastal and maritime regions classified based on the intensity of land-sea interactions (economic activities, flows of goods, people and information environmental pressures). These interactions are greatest in the Core and at their lowest in the Wilderness.

Fig. 11.1 ESaTDOR (European Seas Territorial Development and Risks) LSI typology of European maritime regions. Source: Based on University of Liverpool (2013, p. 6) 
Another strand of LSI-related activity has been supported by DG Environment and is reflected in the publication of an LSI guide for MSP (DG Environment 2018). This includes a scoping of environmental, socio-economic and technical LSI issues in relation to eight key marine development sectors: Aquaculture, desalination, fisheries, marine cables and pipelines, minerals and mining, ports and shipping, tourism and coastal recreation, and offshore energy. It then examines how those engaged in MSP might respond to these in various stages of their plan making. In this way, the guide is a helpful step forward in operationalising LSI understanding within MSP.

A third area of activity is, however, the main source of discussion in the remainder of this chapter, and this relates to work undertaken by the European MSP Platform which is supported by DG Mare. This work was prompted by the MSP Expert Group which advises the European Commission on the roll out of the MSP Directive. In 2017, the expert group identified LSI as an area of particular concern for MSP practitioners, and in response, a conference to examine MSP and LSIs was held in Malta in June 2017, which was attended by over 70 stakeholders from across European seas. This initiative provided a valuable forum to discuss current understanding of LSI issues among European MSP practitioners.

In preparation for the event, the authors of this chapter developed a framework to examine the topic (European MSP Platform 2017a) (see Fig. 11.2). This reflected previous studies and recognised that LSI is a complex phenomenon, involving both natural processes across the land-sea interface and the interactions with human activities on both land and sea. To address LSI the framework proposes that MSP authorities and other stakeholders should, first, seek to understand the dynamics involved, and, second, find institutional mechanisms that are most suited to managing LSI within their particular governance context. The framework acknowledges that there may be a range of options available, involving different types and spatial scales of intervention. The different dimensions of the framework are explained below.

\subsection{The Dynamics of Land-Sea Interactions}

Within the framework, interactions between the land and sea are broadly grouped into two categories-bio-geochemical processes and socio-economic activities-which are closely interrelated and dynamic in their character and expression.

Of the two categories bio-geo-chemical processes in particular have been the subject of a significant number of European research projects and associ- 




Fig. 11.2 Framework for addressing LSI. Source: Based on European MSP Platform (2017a)

ated efforts to inform the practices of planning and management stakeholders. One example is work undertaken in relation to Danish Marine Waters in response to obligations under the Oslo-Paris (OSPAR) Convention, which involved an assessment of factors and parameters that cause, control or respond to eutrophication of the sea. This presents in a simple graphic way key landward sources of marine pollution (see Ærtebjerg et al. 2003, p. 11).

Another example is the Celtic Seas Partnership LIFE funded project which brought together marine and landward stakeholders, governments and the scientific community within the Celtic Seas to find workable ways of supporting the implementation of the Marine Strategy Framework Directive (MSFD) and its ambition to achieve Good Environmental Status of European Seas. One of the outputs of this project was a set of guidelines for those engaged in terrestrial planning explaining how they might support MSFD efforts. The guidelines are useful in providing a simple written account of how landward development can impact on the health of the marine environment (University of Liverpool 2016a).

For example, they explain that the sea is the major sediment and nutrient sink for the land and that pollutants and sediments from land-based activities released into water and air are ultimately likely to find their way to the sea, creating pressures on the functioning of marine and coastal ecosystems. In 
terms of the water environment, the guidelines highlight that marine life relies on good water quality and habitat integrity to live and function well and to provide many of the ecosystem services humans rely on, such as seafood and waste regulation. However, marine water quality can be significantly affected by the effluents and sediments from land-based sources that reach the sea from rivers and direct runoff. Equally, atmospheric emissions (including carbon dioxide) from landward activities are a key cause of ocean acidification as these get transported over the oceans where they fall with rain into the sea. The sea absorbs carbon dioxide, but in the process, this makes the sea more acidic. This can have an impact on many animals in the sea which are adapted to less acidic conditions. In particular, animals that have shells or external skeletons, such as coral reefs, are at risk. This can also impact upon marine industries such as shellfish aquaculture.

In addition, the guidelines emphasise that human-induced climate change mainly from land-based activity has major implications for marine ecosystems. For example, increased storm activity combined with sea-level rise can have important implications for land use due to coastal flooding and erosion. At the same time, an increase in sea temperature will affect the natural range of species which are adapted to colder or warmer temperatures. The sea level will also change, leading to a change in coastal habitats, meaning that current intertidal habitats may reduce in extent or be lost and replaced by different habitats. Any landward activity that contributes to global warming will therefore also have implications for the sea.

Finally, the guidelines note that landward development can result in disturbance to and loss of critical coastal and marine habitats which provide many services such as regulating coastal erosion, flood protection, food production and opportunities for recreation and leisure. They indicate that poorly planned coastal development can have direct, indirect and unintentional impacts on these natural services, the negative impacts of which can significantly outweigh the benefits of the original development.

To assist terrestrial planning stakeholders in assessing the impact of their activities on the marine environment, the guidelines include a checklist of pressures on marine ecosystems that can arise from landward development, which shows how these can impact on different MSFD Good Environmental Status descriptors (See Fig. 11.3).

The discussion above provides some examples of the complex interactions between bio-geochemical processes and socio-economic activities and their impacts on the marine environment. However, in order to develop a rounded understanding, the LSI framework indicates that it is also important to examine relationships from a socio-economic led perspective as well. 


\begin{tabular}{|c|c|c|c|c|c|c|c|c|c|c|c|}
\hline Pressure Descriptor &  & 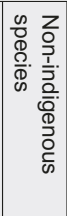 &  &  &  & 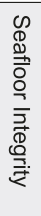 & 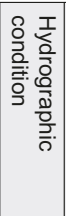 & 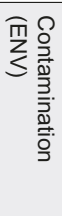 & 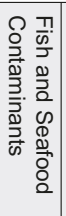 & 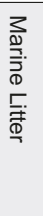 & 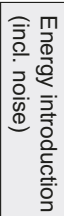 \\
\hline Abrasion (physical disturbance to habitats) & $\mathrm{x}$ & & & $\mathrm{X}$ & & $x$ & & $\mathrm{x}$ & & & \\
\hline Barrier to species movement & $\mathrm{x}$ & & $\mathrm{x}$ & $x$ & & & & & & & \\
\hline $\begin{array}{l}\text { Change in wave exposure (alteration of } \\
\text { normal regime) }\end{array}$ & $\mathrm{x}$ & & $x$ & $x$ & & $x$ & $x$ & & & & \\
\hline Changes in Siltation (above natural levels) & $\mathrm{x}$ & & $\mathrm{x}$ & $\mathrm{X}$ & & $x$ & & & & & \\
\hline Electromagnetic changes & $\mathrm{x}$ & & $x$ & $x$ & & & $\mathrm{X}$ & & & & \\
\hline $\begin{array}{l}\text { Emergence regime changes (alteration of } \\
\text { natural regime) }\end{array}$ & $\mathrm{x}$ & & & $x$ & & $x$ & $\mathrm{x}$ & & & & \\
\hline Input of organic matter (above natural levels) & $\mathrm{x}$ & & $\mathrm{x}$ & $\mathrm{x}$ & $x$ & $x$ & & & $\mathrm{x}$ & & \\
\hline $\begin{array}{l}\text { Introduction of microbial pathogens (above } \\
\text { natural levels) }\end{array}$ & $x$ & & $\mathrm{x}$ & $\mathrm{x}$ & & $\mathrm{x}$ & & & $\mathrm{X}$ & & \\
\hline $\begin{array}{l}\text { Introduction of Non-Indigenous Species and } \\
\text { Translocations }\end{array}$ & $\mathrm{x}$ & $\mathrm{X}$ & $\mathrm{x}$ & $\mathrm{X}$ & $x$ & $\mathrm{x}$ & & & & & \\
\hline $\begin{array}{l}\text { Introduction of Non-synthetic compounds } \\
\text { (e.g. heavy metals, oils) (above natural } \\
\text { levels) }\end{array}$ & $x$ & & $\mathrm{x}$ & $x$ & & $x$ & & $\mathrm{x}$ & $x$ & & \\
\hline $\begin{array}{l}\text { Introduction of Radionuclides (above natural } \\
\text { levels) }\end{array}$ & $x$ & & $\mathrm{x}$ & $x$ & & $x$ & & $\mathrm{x}$ & $x$ & & \\
\hline $\begin{array}{l}\text { Introduction of Synthetic compounds (e.g. } \\
\text { pesticides, pharmaceuticals) }\end{array}$ & $x$ & & $x$ & $x$ & & $x$ & & $\mathrm{X}$ & $\mathrm{x}$ & & \\
\hline Introduction of Litter (all types) & $\mathrm{x}$ & & $x$ & $x$ & & $x$ & & $x$ & $\mathrm{x}$ & $\mathrm{x}$ & \\
\hline Nitrogen and phosphorus enrichment & $\mathrm{x}$ & & $\mathrm{x}$ & $\mathrm{x}$ & $x$ & $x$ & & & $\mathrm{x}$ & & \\
\hline $\mathrm{pH}$ changes (alteration of normal $\mathrm{pH}$ regime) & $\mathrm{x}$ & & $\mathrm{x}$ & $\mathrm{x}$ & & $x$ & $x$ & & & & \\
\hline $\begin{array}{l}\text { Salinity changes (alteration of normal salinity } \\
\text { regime) }\end{array}$ & $x$ & & $x$ & $x$ & & $x$ & $x$ & & & & \\
\hline $\begin{array}{l}\text { Habitat change (due to sealing with new } \\
\text { materials (e.g. concrete) or loss to land (land } \\
\text { reclaim)) }\end{array}$ & $x$ & & $x$ & $x$ & & $x$ & & & & & \\
\hline $\begin{array}{l}\text { Selective extraction of fauna and flora (e.g. } \\
\text { due to fishing, collecting, recreational har- } \\
\text { vesting, loss on cooling inlets) }\end{array}$ & $x$ & & $\mathrm{x}$ & $x$ & & $x$ & & & & & \\
\hline $\begin{array}{l}\text { Smothering of flora and/or fauna (due to } \\
\text { addition of materials onto natural habitat } \\
\text { where there is change in the properties of } \\
\text { the habitat but the habitat is not lost) }\end{array}$ & $x$ & & & $x$ & & $x$ & & & & & \\
\hline $\begin{array}{l}\text { Thermal changes (alteration of natural } \\
\text { temperature regime) }\end{array}$ & $x$ & & $x$ & $x$ & $x$ & $x$ & $x$ & & & & \\
\hline $\begin{array}{l}\text { Underwater noise (outside of natural levels } \\
\text { of noise) }\end{array}$ & $x$ & & $x$ & $x$ & & & & & & & $X$ \\
\hline $\begin{array}{l}\text { Water flow rate changes (alteration of normal } \\
\text { water flow regime) }\end{array}$ & $x$ & & $x$ & $x$ & $x$ & $x$ & $x$ & & & & \\
\hline $\begin{array}{l}\text { Emissions (leading to changes in } \\
\text { environmental drivers like temperature or } \\
\text { acidity resulting from climate change) }\end{array}$ & $x$ & & $x$ & $x$ & $x$ & $x$ & $X$ & & & & \\
\hline
\end{tabular}

Fig. 11.3 Land-sea pressure impact matrix. Source: Based on University of Liverpool (2016a, p. 16) 
In this respect, the LSI and MSP brochure published by DG Environment (DG Environment 2018) provides a helpful reference. For example, its scoping of socio-economic interactions of marine cables and pipeline development identifies potential benefits to landward communities in the form of employment and income regionally and nationally with respect to direct and ancillary activities. However, it also raises questions about potential displacement effects which might have socio-economic consequences. It notes that fishing vessels may be excluded from cable corridors or landfall sites or these could require changes in fishing activity such as shifts in fishing gear which may have negative impacts on landings, fishermen's income, jobs and fishing communities. A similar socio-economic scoping undertaken for marine mining and minerals highlights that the sector could also bring socio-economic benefits in the form of employment and income regionally and nationally including that related to ancillary sectors such as exploration services and ship building and secondary activities such as construction. In addition, it suggests that tourism and recreation might benefit from such activity if it is directed to the provision of material for beach recharge and coast protection. Similarly there could be wider socio-economic benefits to coastal communities if the activity is associated with the development of flood defence structures. On the other hand, possible negative consequences of marine mining and minerals activity could relate to its potential restriction on offshore energy development, as this may need to be excluded from extraction areas for the duration of an extraction licence. From these scoping examples it can be seen that the socio-economic impacts of human uses of the marine environment can be both positive and negative and the brochure is helpful in indicating the type of assessments that might aid MSP decision-making taking account of socioeconomic LSI concerns.

It is interesting to observe however, that this LSI analysis with its MSP focus tends towards a seaward perspective and that a complementary view on LSI which is arguably more landward in its orientation is perhaps evident in the European Commission initiatives related to Blue Growth. Since the inception of the EU's Blue Growth Strategy in 2012, it has been clear that European seas and oceans are increasingly seen as one of the important drivers for the European economy and that MSP is regarded a key tool for achieving sustainable Blue Growth. In a review published in 2017, it was estimated that Europe's maritime industries employed over 5 million people and generated almost EUR 500 billion a year for the European economy. The potential to create many more jobs was also noted, with Organization for Economic Cooperation and Development (OECD) forecasts suggesting that the value of the global ocean economy could more than double by 2030 . 
Significant growth rates were already evident in some sectors in Europe, for example, in the rapid development of offshore wind farms which have since 2012 emerged as a major contributor to European employment accounting for around 150,000 jobs (EC 2017a). Increasing recognition of the economic significance and potential for growth in maritime sectors is prompting a new phase of LSI research with a more direct socio-economic and landward orientation. This is reflected in the Blue Growth strand of Horizon 2020 research programme (EC 2017b) as well as research directly commissioned by different arms of the European Commission such as DG Mare. An example that is helpful to the current discussion is a study of Scenarios and Drivers for Sustainable Growth from the Oceans, Seas and Coasts (Ecorys 2012). Out of an identified 27 maritime economic activities of significance in Europe, this study examined 11 sectors which were considered to offer the most growth potential (short sea shipping, marine aquatic products, blue biotechnology, oil and gas, offshore wind, ocean renewable energy, marine minerals, coastal tourism, cruise tourism, coastal protection, maritime security and surveillance and environmental monitoring). Value chain analysis formed a key part of the investigation. A summary example of its application to short sea shipping together with an outline of the approach is shown in Fig. 11.4. Value chain analysis explores the landward
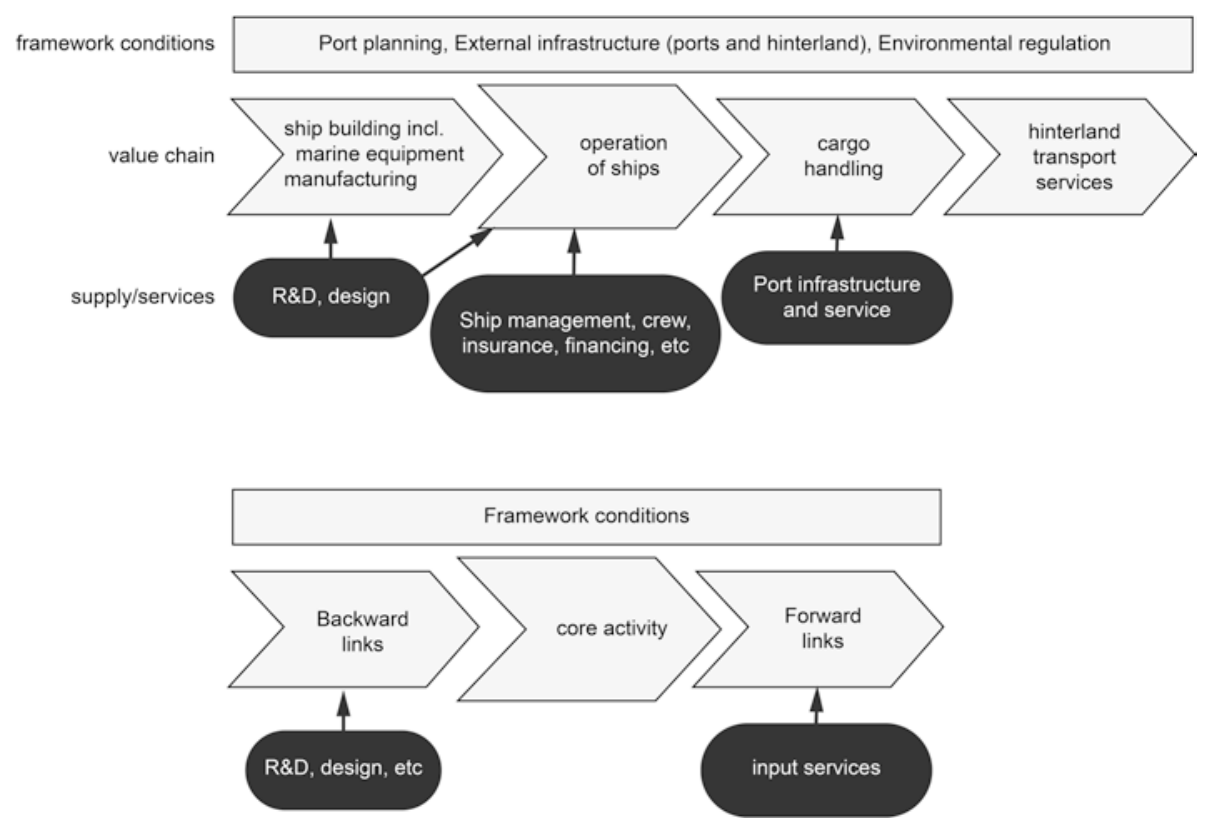

Fig. 11.4 Example of LSI value chain analysis. Source: Based on Ecorys (2012, pp. 32, 55) 
implications of maritime sectors including direct employment associated with the core activity and indirect employment associated with backward and forward sector linkages. These aspects are all affected by surrounding framework conditions that provide the context for the maritime economic activities to develop (e.g. inland port and transport infrastructure, and training and research institutions). It is perhaps important to note that many aspects of these framework conditions lie beyond the control of MSP but are influenced by the policy and activities of terrestrial agencies including those related to terrestrial planning. Further development of this value chain analysis is a central component of the ESPON funded MSP-LSI project mentioned above and it is envisaged that it will be a core element in the LSI guidelines which will be produced by the project to help both MSP and terrestrial planning regimes understand and address LSI issues.

Although value chain analysis seems to be emerging as key tool in LSI investigation in relation to socio-economic activities, some might argue that the social aspects of LSI are still under-represented. A possible means of responding to this is by incorporating ecosystems services perspectives in LSI analysis. Ecosystem Services are defined as the benefits human beings can obtain from ecosystems (Millennium Ecosystem Assessment 2005, p. v.) and traditionally are separated into four categories: Provisioning, Regulating, Supporting and Cultural Services. Although not without its critics and limitations, an Ecosystem Services approach does offer the potential to look deeper into LSI considerations not least through its identification of Cultural Services. These are generally considered to be those non-material benefits people obtain from interaction with their surroundings and can take many different forms, from aesthetic appreciation of the natural environment to artistic inspiration, using different spaces or settings for activities such as leisure, education, improving health and well-being, spiritual enrichment, appreciation of symbols, history and diverse cultures. In this regard, the Nature's Services and the Sea resource pack which was also an output of the Celtic Seas Partnership project (University of Liverpool 2016b) could provide inspiration for how social aspects of LSI might be given more attention.

\subsection{Legislative and Institutional Arrangements to Address Land-Sea Interactions}

Having provided guidance on the dynamics of land-sea interaction, the LSI framework shown in Fig. 11.2 then indicates that these may be addressed through a variety of legislative and institutional arrangements which may 
have different spatial configurations in terms of land-sea coverage and operate at different spatial scales. A key point to emphasise is that local circumstances will determine which option might be most appropriate and the choice will be determined by a wide range of factors including existing institutional and legislative structures, cultural norms and practices, and geography. The following section outlines different LSI governance options with reference examples in Europe.

One option that is available is for LSI interactions to be managed through ICM initiatives. For example, Croatia is developing a Joint Management Strategy for Marine Environmental and Coastal Zone Areas and a related Action Programme. The strategy links to its obligations under the 1995 Barcelona Convention for the Protection of the Marine Environment and the Coastal Region of the Mediterranean and its ICM Protocol which was adopted in 2010. LSI considerations are fundamental to this protocol which reflects an understanding that the preservation and sustainable development of the Mediterranean requires a specific integrated approach at the level of the Mediterranean basin as a whole and of its coastal States including their inland areas. The protocol calls for ICZM activities at both sea-basin and national scales and specifically mentions connection to land policy and for states to put in place economic, financial and/or fiscal instruments intended to support local, regional and national initiatives for the integrated management of coastal zones. This emphasis on ICZM approaches to LSI is particularly relevant to the Mediterranean as sea borders between states are still to be agreed, meaning that the scope for MSP (sea focussed) activity is restricted. However, from an LSI perspective, this means that the Mediterranean experience merits close attention, as this is a region where LSI issues are a particular focus of attention.

Some countries have chosen to maintain separate terrestrial and marine planning systems whilst providing for land-sea interactions to be taken into consideration. This is the case in England where marine planning and terrestrial planning are separate but with an overlapping area of jurisdiction in the intertidal zone. Despite this, LSI issues are addressed in a number of ways. First, the UK Marine Policy Statement, which is the key guidance for marine planning in England, is also identified as guidance for terrestrial planning. Equally, the National Planning Policy Framework for inland planning authorities includes sections on maritime matters and is also a relevant guidance for marine planners. There is also a formal duty to cooperate between the two systems, and at a local level, a mechanism is available to put in place a formal 'coastal concordat' coordinating the consenting processes for developments within the coastal zone. In addition, the planning inspectorate's checklist related to the 'test of soundness' of terrestrial development plans now includes 
a range of requirements related to marine matters (University of Liverpool 2016c).

Another option is for local and regional scale terrestrial plans to extend into the marine environment with a view to addressing LSI within these areas. In France, for example, since 2000, an instrument called the Schéma de Cohérence Territorial (SCOT) has been available as an optional plan prepared by communes. The SCOT sets out strategic goals for the area it covers and it has been possible to include a specific chapter which can stand as a schéma de mise en valeur de la mer (SMVM) and integrate maritime concerns into the plan. (University of Liverpool 2016c). In Germany also for some time the Lander authorities have had a planning remit which extends over their adjoining sea areas. An example is Mecklenburg-Vorpommern where work started on the first marine spatial plan in 2002 when the concept was very new. The MecklenburgVorpommern plan came into force in 2005 and was revised in 2016. In the recent version, the approach has been to extend the terrestrial plan into the sea $(12 \mathrm{~nm})$ in order to create one holistic plan with a common legal framework. In preparing the plan, a process of screening LSIs was undertaken in order to establish what kind of interactions were taking place, what data was available and who was responsible for managing them. As a result of this approach, most of the stipulations in the updated State Development Programme are regulations that deal with LSIs (European MSP platform 2017b).

The emergence of integrated planning approaches as a means of addressing LSI is also seeing the creation of national strategies which encompasses both terrestrial and marine areas. This is the approach taken by the Netherlands, for example, in the National Policy Strategy for Infrastructure and Spatial Planning (Ministry of Infrastructure and Environment 2011). This includes a National Spatial Structure map which extends over areas of Dutch jurisdiction in the North Sea, and the document develops a comprehensive vision for the development of Dutch territory looking to 2040. An interesting feature of the document is that it doesn't separately consider marine areas, but LSI matters are interwoven throughout the plan which aims to support the ambition for the Netherlands to develop in a competitive, accessible, liveable and safe manner. Malta takes a similar approach through their Strategic Plan for Environment and Development. This is an overarching plan covering both land and sea and also acts as the national Maritime Spatial Plan. Again LSI issues permeate the document, but it does include a separate chapter on the Coastal Zone and Marine Area (Government of Malta 2015).

LSI can also be managed on a larger, sea-basin scale and a prominent example of this is the Baltic Sea Region (BSR). This region has much experience with transboundary cooperation with an appreciation of LSI as a central driv- 
ing force. For example, within the frame of the Baltic Marine Environment Protection Commission (or Helsinki Commission [HELCOM]), a Baltic Sea Action Plan (HELCOM 2007) for environmental protection has been developed with, for example, landward responses to eutrophication concerns a major focus of attention. The region also has developed the VASAB Long-term Vision for the BSR (Szydarowski and VASAB Committee on Spatial Development 2009), which recognises the Baltic Sea as a unifying factor and a shared resource and proposes a list of actions to stimulate territorial development potentials in the region related to urban networking and urban rural relations, accessibility and management of the Baltic Sea. LSI issues of a more socio-economic nature are prominent here. As is discussed in other chapters in this volume, activities related to HELCOM and VASAB have spawned a range of Baltic Sea-wide endeavours related to MSP with LSI a common thread running through them.

LSI can also be managed within sectors themselves, such as oil and gas, and tourism, sometimes operating at a sea-basin scale. For example, the INTERREG MED-funded project CO-EVOLVE, which started at the beginning of 2017, is analysing and promoting the co-evolution of human activities and natural systems in coastal tourist areas in the Mediterranean, allowing for the sustainable development of tourist activities, based on the principles of ICZM and MSP. CO-EVOLVE recognises that a key challenge for sustainable coastal and maritime tourism development is the strengthening of cooperation among regions and the joint development and transferring of approaches, tools, guidelines and best practices. It brings together an analysis at a Mediterranean scale of threats and enabling factors for sustainable tourism with local studies on seven representative pilot areas. The aim is to demonstrate through pilot actions the feasibility and effectiveness of an ICZM/MSP-based planning process.

The framework presented in Fig. 11.2 also notes that it is technically possible that LSI could be addressed by extending the remit of MSP inland, in contrast to extending a terrestrial planning area seawards. However, this is not an approach that appears to have been adopted so far.

It is clear from the above examples that LSI can be addressed at a variety of spatial scales. These include:

- Local areas, such as ICZM partnerships and economically driven initiatives, involving municipalities and other local interests

- Sub-national planning territories, such as maritime plan areas, involving MSP authorities working in collaboration with coastal and maritime stakeholders 
- National territories, where a national strategy or plan, covering the whole of the nation's waters, and possibly its land area as well, may guide LSI efforts

- Sea basins/transnational regions, where transnational cooperation may produce a strategy or protocol for guiding national LSI efforts and ensuring ongoing cross-border cooperation

These scales are not mutually exclusive. For example, a higher-level strategy may be implemented or supplemented at a sub-national or local level by other instruments. A key notion underlying the framework presented in Fig. 11.2 is that alternative governance approaches to addressing LSI are available, and what is the most suitable in a particular context must be informed by local factors including existing institutional arrangements for spatial planning and management.

\section{Some Reflections on the LSI Framework}

This penultimate section of the chapter draws upon the discussions of the different aspects of the framework at the conference on LSIs held in Malta, June 2017 (European MSP platform 2017b). Summary points related to each European sea basin are presented in Tables 11.1, 11.2, 11.3, 11.4 and 11.5 and the key findings from the workshop are then outlined below.

\subsection{Context Matters}

Although many LSI issues are common to all European seas, as Tables 11.1, $11.2,11.3,11.4$ and 11.5 reveal, the detailed experience of LSI varies in significant ways between countries and sea basins. This reflects differences in physical/human geography and legal/administrative arrangements as well as wider culture norms and perspectives. For example, the LSI experience of small islands was considered to be very different from that of large countries with small areas of coastline. This suggests that while there is much scope for developing common understanding and collaborative approaches to LSI, localised variations highlight the value in fostering diversity in LSI-related practices. 
Table 11.1 LSI issues and arrangements in the European Atlantic

\begin{tabular}{|c|c|}
\hline Key LSI issues & Institutional and legislative arrangements \\
\hline $\begin{array}{l}\text { - Coastal } \\
\text { erosion } \\
\text { - Climate } \\
\text { change } \\
\text { - } \quad \text { Air quality } \\
\text { associated } \\
\text { with ports } \\
\text { and related } \\
\text { activities } \\
\text { - Landscape } \\
\text { and visual } \\
\text { impacts of } \\
\text { windfarms }\end{array}$ & $\begin{array}{l}\text { OSPAR } \\
\text { OSPAR: Protecting and conserving the Northeast Atlantic and its } \\
\text { resources is the mechanism for governments to cooperate on the } \\
\text { implementation of the Convention for the Protection of the } \\
\text { Marine Environment of the Northeast Atlantic. OSPAR works on a } \\
\text { number of fields including biodiversity and ecosystems, hazardous } \\
\text { and radioactive substances, human activities and offshore } \\
\text { industries. OSPAR had installed a dedicated working group on } \\
\text { MSP that is inactive at this time. } \\
\text { Atlantic Strategy } \\
\text { The Atlantic Strategy as it stands provides directions for investment } \\
\text { and funding relevant to LSI issues. As it is high level, its influence is } \\
\text { rather intangible and bottom-up interaction is limited at present. } \\
\text { Atlantic Arc Commission } \\
\text { The Atlantic Arc Commission is one of the Conference of the } \\
\text { Peripheral Maritime Region's (CPMR) six geographical } \\
\text { Commissions. In the general work of the CPMR, LSI is being looked } \\
\text { at in terms of implementation of the MSP Directive with reference } \\
\text { to Articles } 4,6 \text { and 7, but also Article 9, which includes a } \\
\text { requirement for consulting with other relevant parties and } \\
\text { stakeholders. } \\
\text { Voluntary and Sectoral Fora } \\
\text { For example, Fisheries Advisory Councils provide mechanisms for } \\
\text { discussion and knowledge and experience sharing concerning a } \\
\text { range of LSI issues. There are different levels of involvement in } \\
\text { different Member States across the Atlantic Ocean. }\end{array}$ \\
\hline
\end{tabular}

\subsection{Integrated Perspectives Are Important}

The workshop discussions confirmed that interactions between land and sea and between environmental, socio-economic and governance elements are highly complex. While disaggregation of different LSI elements can aid understanding and help direct action, it was felt that integrated 'whole system' perspectives and approaches are required to address LSI in an effective way. The need to develop a broad-based understanding of LSI issues among both terrestrial and marine stakeholders and foster integrated 'territorial' approaches to planning and management across land and sea was an important overarching message. 


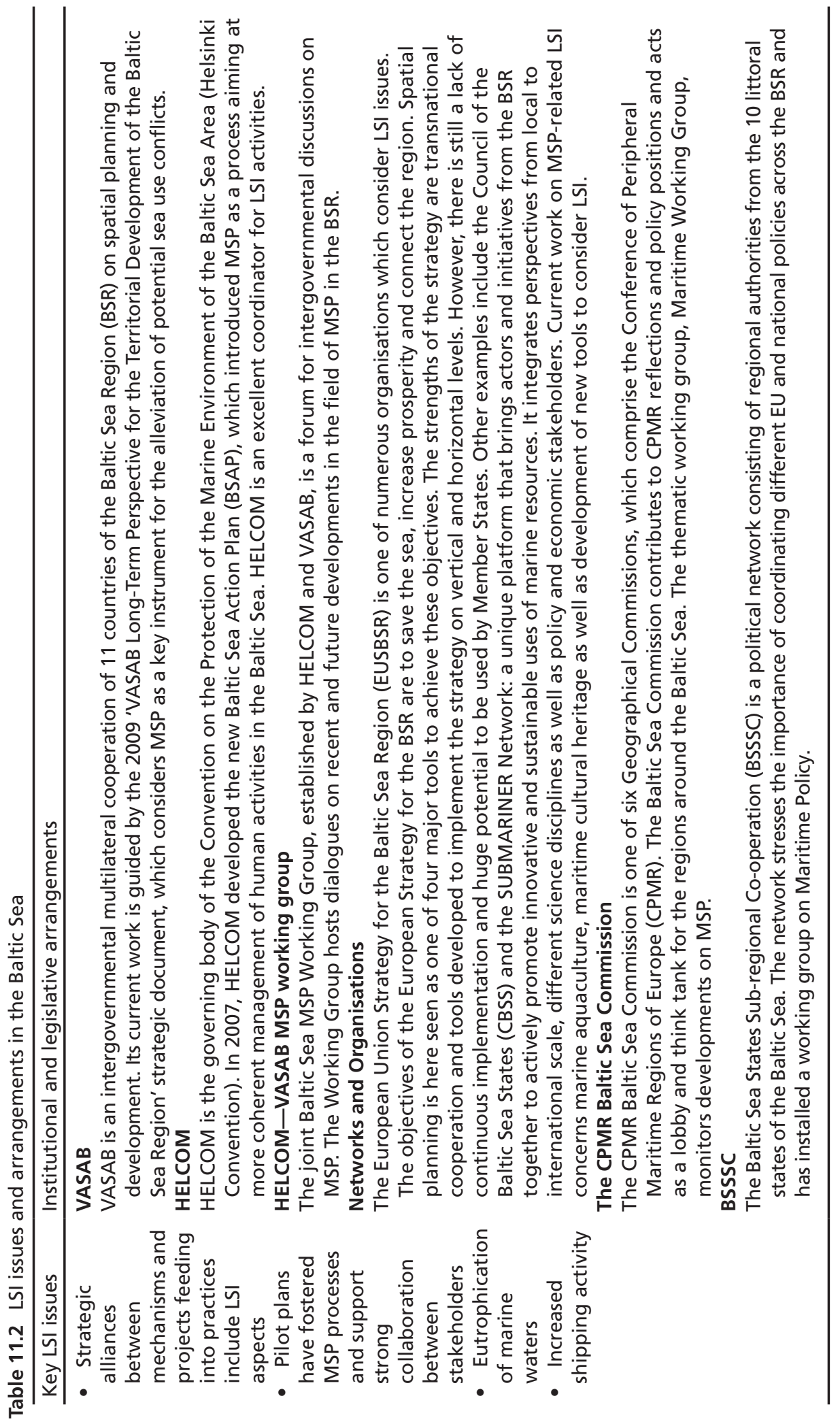


Table 11.3 LSI issues and arrangements in the Black Sea

\begin{tabular}{|c|c|}
\hline Key LSI issues & Institutional and legislative arrangements \\
\hline $\begin{array}{l}\text { - Mass coastal } \\
\text { tourism and related } \\
\text { environmental } \\
\text { impacts } \\
\text { - Lack of accurate } \\
\text { and up to date data } \\
\text { - Geopolitical } \\
\text { barriers to } \\
\text { addressing LSI } \\
\text { - Lack of legislation } \\
\text { and strategies to } \\
\text { deal with LSI }\end{array}$ & $\begin{array}{l}\text { Black Sea Basin Programme } \\
\text { The programme provides opportunities to extend existing } \\
\text { European experience to the Black Sea and is particularly } \\
\text { useful concerning the development of transboundary } \\
\text { cooperation and improving LSI practices through } \\
\text { networking. } \\
\text { Black Sea Commission } \\
\text { The Commission on the Protection of the Black Sea against } \\
\text { Pollution provides an inventory of data, partnership and } \\
\text { governance of relevance to the environmental dimensions } \\
\text { of LSI, as well as challenges related to political issues. It } \\
\text { could take a lead in data standardisation and monitoring } \\
\text { of environmental aspects. }\end{array}$ \\
\hline
\end{tabular}

Table 11.4 LSI issues and arrangements in the Black Sea

\begin{tabular}{|c|c|}
\hline Key LSI issues & Institutional and legislative arrangements \\
\hline $\begin{array}{l}\text { - Transnational } \\
\text { management of supply } \\
\text { chains linking shipping, } \\
\text { port \& inland transport } \\
\text { infrastructure, import/ } \\
\text { export industries } \\
\text { - Offshore renewable } \\
\text { energy developments } \\
\text { and impacts on } \\
\text { shipping/port } \\
\text { accessibility } \\
\text { Difficulties in } \\
\text { transnational } \\
\text { management of LSI as } \\
\text { many issues are country } \\
\text { specific }\end{array}$ & $\begin{array}{l}\text { OSPAR } \\
\text { OSPAR is an international cooperation organisation with } \\
\text { the potential to take responsibility for transnational LSI } \\
\text { issues; however, it is questioned whether or not there is } \\
\text { a mandate for this and if the correct management } \\
\text { systems are in place. } \\
\text { North Sea Commission } \\
\text { The North Sea Commission is a political cooperation } \\
\text { platform for regions across the North Sea. The aim is to } \\
\text { promote common interests, especially concerning EU } \\
\text { institutions, national governments and other } \\
\text { organisations that deal with issues relevant to the } \\
\text { North Sea, including LSI. One of the focus areas of the } \\
\text { North Sea Region } 2020 \text { Strategy is MSP. One of the } \\
\text { thematic working groups, 'Marine Resources', includes } \\
\text { exchange of best practice on ICZM and MSP across the } \\
\text { North Sea. }\end{array}$ \\
\hline
\end{tabular}

\subsection{LSI Challenges and Opportunities}

Discussions also highlighted that efforts to address LSI should focus not only on the challenges raised by LSI but also on finding beneficial synergies and realising the opportunities that LSI can bring. 
Table 11.5 LSI issues and arrangements in the Baltic Sea

\begin{tabular}{ll}
\hline Key LSI issues & Institutional and legislative arrangements \\
\hline - Coastal erosion & Barcelona Convention ICZM Protocol \\
- Climate change & The Protocol is directly concerned with LSI and provides for \\
- Intense transport/ & exchange of experience, but there are different stages of \\
traffic & application between countries. \\
- Urbanisation and & EUSAIR \\
impacts on wider & The macro-regional strategy provides a common political \\
marine environment & agreement for the Adriatic, which is of key relevance to \\
- Institutional & LSI issues, but there is a need to improve the \\
fragmentation & operationability. There is also a need to develop good \\
& practices regarding the integration of ecological and \\
& economic parts. \\
& UNEP MAP/Regional Activity Centres (RACs) \\
In the Mediterranean RACs disseminate information on \\
areas of special protection and marine litter for \\
example and provide informal institutional settings \\
(although there is a desire for more formalised settings) \\
and facilitate networking through events and \\
conferences \\
BLUE MED \\
This initiative strengthens cooperation on Mediterranean \\
issues of relevance to LSI, but the long-term sustainability \\
of the initiative may be a challenge
\end{tabular}

\subsection{The Value of Diversity in Approaching LSI}

It was felt that the LSI framework provides a useful way to structure discussion of different approaches to addressing LSI issues. The conference confirmed that a 'one-size-fits-all' approach to tackling LSI is not appropriate. Variations in context mean that what might be relevant and work well in one area might not be appropriate in another. However, it was felt that there was much merit in sharing different experiences.

\subsection{Learning from ICZM}

A recurring theme was that Europe's experience of ICZM, which had been developed to address many LSI issues, remained a valuable source of inspiration and in some instances could provide established mechanisms that could be built upon in finding new ways to integrate maritime and terrestrial planning and address LSI issues in contemporary times. 


\subsection{Opportunity for Cooperative Sea-Basin Approaches to LSI}

In all sea basins, delegates identified established transnational institutional and legislative arrangements that could help to address LSI. These ranged from institutions associated with international conventions such as HELCOM and OSPAR; EU-supported sea-basin strategies and regional development programmes/projects; mechanisms associated with the delivery of European Directives including the MSFD, Water Framework and MSP Directives; and various other transnational fora ranging from the formal to the informal. However, it was noted that many of these organisations were only partial in their coverage of LSI issues and/or their land/sea responsibilities and that the scope for improved synergy and joined up action to better address LSI at a regional sea scale was great.

\subsection{Connecting Strategic and Local Level Action}

Equally, it was noted that all European sea basins have agencies and projects of various sorts at national and local levels for addressing LSI issues. Again it was noted that in many cases these were also partial in their scope/remit. It was also recognised that there was often a gap in understanding between the various levels that hampered effective responses to LSI. More generally, it was considered that there is a need to increase knowledge of LSI among all stakeholders and that this requires improved LSI-related data collection.

\subsection{The Importance of Sea-Basin-Scale Approaches}

Overall, it was felt that the MSP Directive and new MSP arrangements presented new opportunities to address LSI issues that have been investigated for many years. However, at the same time, it was important to acknowledge that MSP is only one of many mechanisms which can be used to address LSI. For example, DG MARE has recognised the importance of stepping back from national MSP efforts and has provided support to look at maritime issues at sea-basin or sub-sea-basin scale. Other forms of European funding have also been made available to support LSI-related initiatives, and consequently there are many examples of successful projects that have addressed LSI. Whilst further EU funding for projects can provide an avenue for continuing this work, it was felt that this was not a sustainable mechanism in the long term. Instead, 
the Baltic Sea HELCOM-VASAB collaboration was put forward as a notable example showing how countries can work together on an ongoing basis to address LSI at a transnational scale, and it was felt that this provided a useful model that other sea basins could follow.

\section{Conclusions}

This chapter has explored the relationship between MSP and LSI and in so doing has hopefully provided some useful reminders about the origins and scope of MSP but also offered some inspiration for future directions for MSP and for ocean governance more generally. By looking back at some of the core documents and experience that has framed the development of MSP, we can see that LSI considerations were prominent in its evolution and remain central to MSP activities today. However, consideration of LSI issues related to bio-geochemical processes highlights that MSP has only a small part to play in addressing many of the environmental challenges facing the world's oceans. Equally, investigation of LSI issues related to socio-economic activities indicates that MSP is only one element in a wider governance and economic and social system that influences sea-based activities and that can help to deliver sustainable patterns of Blue Growth. These reflections suggest the need for realism about what MSP can deliver and for more extensive debate about where it sits within existing structures of governance on both land and sea. While the chapter suggests the need to qualify what MSP can achieve, it also perhaps reveals the valuable role that it is and can play in providing an arena for discussion about human relationships with the world's oceans and in highlighting how continuing innovation in governance arrangements seem to be needed. One area of innovation in particular emerges from the commentary presented here which connects to notions of integrated governance, ecosystem-based management and the Ecosystem Approach as well as LSI. This relates to the development of a new era of what might be termed Territorial Spatial Planning-integrated planning which is place based and spans land and sea. This is a recurring feature in many efforts to address LSI presented above, and examples are evident at all levels and in different regions. It is as yet developing in an embryonic and seemingly haphazard manner, but a groundswell seems to be emerging that this is a key way forward. Whether TSP approaches develop and are helpful in addressing LSI challenges and opportunities and what this might mean for the evolution of MSP will be key subjects of enquiry in the years ahead. 
Acknowledgements We are grateful to the project 'Economy of maritime space' funded by the Polish National Science Centre for contributing the Open Access fee for this chapter and facilitating our discussions and preparation of the book.

\section{References}

Ærtebjerg, G., Andersen, J. H., \& Hansen, O. S. (Eds.). (2003). Nutrients and Eutrophication in Danish Marine Waters. A Challenge for Science and Management. Copenhagen: Danish National Environmental Research Institute.

DG Environment. (2018). Land-Sea Interactions in Maritime Spatial Planning. Brussels: European Commission.

Douvere, F. (2008). The Importance of Marine Spatial Planning in Advancing Ecosystem-Based Sea Use Management. Marine Policy, 32(5), 762-771.

Ecorys. (2012). Blue Growth Scenarios and Drivers for Sustainable Growth from the Oceans, Seas and Coasts: Final Report. Brussels: European Commission, Directorate General for Maritime Affairs and Fisheries.

Ehler, C. (2014). A Guide to Evaluating Marine Spatial Plans. IOC Manuals and Guides No. 70, ICAM Dossier 8. Paris: UNESCO, Intergovernmental Oceanographic Commission UNESCO IOC, 96 pp.

Ehler, C. (2018). Marine Spatial Planning: An Idea Whose Time Has Come. In Offshore Energy and Marine Spatial Planning (pp. 6-17). Routledge.

Ehler, C., \& Douvere, F. (2009). Marine Spatial Planning: A Step-by Step Approach Towards Ecosystem-based Management. Manual and Guides No 153 ICAM Dossier No 6. Paris: Intergovernmental Oceanographic Commission UNESCO IOC, 99 pp.

EC. (1999). Towards a European Integrated Coastal Zone Management (ICZM) Strategy General Principles and Policy Options. Luxembourg: Office for Official Publications of the European Communities.

EC. (2014). DIRECTIVE 2014/89/EU Establishing a Framework for Maritime Spatial Planning. Brussels: European Commission.

EC. (2017a). Report on the Blue Growth Strategy Towards more Sustainable Growth and Jobs in the Blue Economy. Brussels: European Commission.

EC. (2017b). Research EU Results Pack All Aboard for Better Marine Stewardship Through Research and Innovation. Luxembourg: The Community Research and Development Information Service (CORDIS).

European MSP Platform. (2017a). Maritime Spatial Planning: Addressing Land-Sea Interaction a Briefing Paper. Brussels: European Commission, DG Mare.

European MSP Platform. (2017b). Maritime Spatial Planning Conference Addressing Land-Sea Interactions Conference Report. Brussels: European Commission, DG Mare.

Foley, M. M., Halpern, B. S., Micheli, F., Armsby, M. H., Caldwell, M. R., Crain, C. M., Prahler, E., Rohr, N., Sivas, D., Beck, M. W., \& Carr, M. H. (2010). Guiding Ecological Principles for Marine Spatial Planning. Marine Policy, 34(5), 955-966. 
Future Earth Coasts. (2018). Our Coastal Futures: A Strategy for the Sustainable Development of the World's Coasts. Cork: Future Earth Coasts.

Government of Malta. (2015). Strategic Plan for Environment and Development. Santa Venera: Government of Malta.

HELCOM. (2007). HELCOM Baltic Sea Action Plan. HELCOM: Helsinki.

Maes, F. (2008). The International Legal Framework for Marine Spatial Planning. Marine Policy, 32(5), 797-810.

Millennium Ecosystem Assessment. (2005). Ecosystems and Human Well-Being Synthesis. Washington, DC: Island Press.

Ministry of Infrastructure and Environment. (2011). Summary National Policy Strategy for Infrastructure and Spatial Planning: Making the Netherlands Competitive, Accessible, Liveable and Safe. The Hague: Ministry of Infrastructure and Environment.

Nautical Institute and the World Ocean Council. (2013). The Shipping Industry and Marine Spatial Planning: A Professional Approach. London: Nautical Institute.

Pınarbaşı, K., Galparsoro, I., Borja, Á., Stelzenmüller, V., Ehler, C. N., \& Gimpel, A. (2017). Decision Support Tools in Marine Spatial Planning: Present Applications, Gaps and Future Perspectives. Marine Policy, 83, 83-91.

Ramesh, R., Chen, Z., Cummins, V., Day, J., D’Elia, C., Dennison, B., Forbes, D. L., Glaeser, B., Glaser, M., Glavovic, B., \& Kremer, H. (2015). Land-Ocean Interactions in the Coastal Zone: Past, Present \& Future. Anthropocene, 12, 85-98.

Soininen, N., \& Hassan, D. (2015). Marine Spatial Planning as an Instrument of Sustainable Ocean Governance. In Transboundary Marine Spatial Planning and International Law (pp. 3-20).

Szydarowski, W., \& VASAB Committee on Spatial Development. (2009). VASAB Long-Term Perspective for the Territorial Development of the Baltic Sea Region. Riga: Vasab Secretariat.

UNESCO and European Commission. (2017). Joint Road Map to Accelerate Marine/Maritime Spatial Planning Processes World Wide. Retrieved July 4, 2018, from http://www.unesco.org/new/fileadmin/MULTIMEDIA/HQ/SC/pdf/Joint_ Roadmap_MSP_v5.pdf.

United Nations Conference on Trade and Development. (2017). Trade and Development Report 2017: Beyond Austerity: Towards A Global New Deal. Geneva: UNCTD.

United Nations General Assembly. (1982). Convention on the Law of the Sea. Retrieved July 4, 2018, from http://www.refworld.org/docid/3dd8fd1b4.html.

University of Liverpool. (2013). ESTaDOR European Seas Territorial Development Opportunities and Risks: Executive Summary. Liverpool: University of Liverpool.

University of Liverpool. (2016a). Marine Proofing for Good Environmental Status of the Sea: Good Practice Guidelines for Terrestrial Planning. Cardiff: WWF, Celtic Seas Partnership.

University of Liverpool. (2016b). Nature's Services and the Sea: A Resource Pack for Marine and Coastal Stakeholders. Cardiff: WWF, Celtic Seas Partnership.

University of Liverpool. (2016c). Marine Proofing for Good Environmental Status of the Sea: Good Practice Guidelines for Terrestrial Planning: Country Fact Sheets. Cardiff: WWF, Celtic Seas Partnership. 
Open Access This chapter is licensed under the terms of the Creative Commons Attribution 4.0 International License (http://creativecommons.org/licenses/by/4.0/), which permits use, sharing, adaptation, distribution and reproduction in any medium or format, as long as you give appropriate credit to the original author(s) and the source, provide a link to the Creative Commons licence and indicate if changes were made.

The images or other third party material in this chapter are included in the chapter's Creative Commons licence, unless indicated otherwise in a credit line to the material. If material is not included in the chapter's Creative Commons licence and your intended use is not permitted by statutory regulation or exceeds the permitted use, you will need to obtain permission directly from the copyright holder. 